\title{
Papers
}

\section{Effect of long term consumption of probiotic milk on infections in children attending day care centres: double blind, randomised trial}

\author{
Katja Hatakka, Erkki Savilahti, Antti Pönkä,Jukka H Meurman, Tuija Poussa, Leena Näse, \\ Maija Saxelin, Riitta Korpela
}

\begin{abstract}
Objective To examine whether long term consumption of a probiotic milk could reduce gastrointestinal and respiratory infections in children in day care centres.

Design Randomised, double blind, placebo controlled study over seven months.

Setting 18 day care centres in Helsinki, Finland. Participants 571 healthy children aged 1-6 years: 282 (mean (SD) age 4.6 (1.5) years) in the intervention group and 289 (mean (SD) age 4.4 (1.5) years) in the control group.

Intervention Milk with or without Lactobacillus GG. Average daily consumption of milk in both groups was $260 \mathrm{ml}$.

Main outcome measures Number of days with respiratory and gastrointestinal symptoms, absences from day care because of illness, respiratory tract infections diagnosed by a doctor, and course of antibiotics.
\end{abstract}

Results Children in the Lactobacillus group had fewer days of absence from day care because of illness (4.9 (95\% confidence interval 4.4 to 5.5$)$ v 5.8 (5.3 to 6.4 ) days, $16 \%$ difference, $\mathrm{P}=0.03$; age adjusted 5.1 (4.6 to 5.6) v 5.7 (5.2 to 6.3 ) days, $11 \%$ difference, $\mathrm{P}=0.09$ ). There was also a relative reduction of $17 \%$ in the number of children suffering from respiratory infections with complications and lower respiratory tract infections (unadjusted absolute $\%$ reduction $-8.6(-17.2$ to -0.1$), \mathrm{P}=0.05$; age adjusted odds ratio 0.75 (0.52 to 1.09$), \mathrm{P}=0.13)$ and a $19 \%$ relative reduction in antibiotic treatments for respiratory infection (unadjusted absolute \% reduction -9.6 ( -18.2 to -1.0$), \mathrm{P}=0.03$; adjusted odds ratio 0.72 (0.50 to 1.03$), \mathrm{P}=0.08$ ) in the Lactobacillus group. Conclusions Lactobacillus GG may reduce respiratory infections and their severity among children in day care. The effects of the probiotic Lactobacillus GG were modest but consistently in the same direction.

\section{Introduction}

Children attending day care centres have a 1.5-3.0 times higher risk of gastrointestinal and respiratory tract infections than children cared for at home or in small family care groups. ${ }^{1-6}$ Increased risk of disease has obvious public health and economic consequences, such as direct medical costs as well as the indirect costs of parents having to take time off work to look after sick children. ${ }^{7-9}$ Prevention of infections in day care is therefore of major importance.

Probiotic bacteria, which beneficially affect the host by improving the intestinal microbial balance, may affect the immune response. Lactobacillus rhamnosus GG, ATCC 53103, a probiotic strain of human origin with widely documented health effects, ${ }^{10}$ influences immune response, both specifically by stimulating antibody production ${ }^{11}$ and non-specifically by enhancing the phagocytic activity of the blood leucocytes. ${ }^{12}$ It promotes recovery from rotavirus diarrhoea ${ }^{11}$ and reduces the incidence of diarrhoea associated with use of antibiotics in children. ${ }^{13}{ }^{14}$ However, most studies of probiotic bacteria have been short term trials. Over a seven month winter period we examined the effect of consumption of milk containing probiotic bacteria on the incidence of gastrointestinal and respiratory infections in children attending day care centres.

\section{Methods}

\section{Participants}

This randomised, double blind, placebo controlled clinical study was carried out in 18 municipal day care centres, in similar socioeconomic areas in north, west, and north east Helsinki. Children aged 1-6 years were recruited through meetings with parents. We excluded children with allergy to cows' milk, lactose intolerance, severe food allergy, and other severe chronic diseases. All the healthy children whose parents gave informed consent were randomised for the trial $(n=594)$. The study protocol was approved by the ethics committee of Helsinki City Health Department.

\section{Intervention}

The intervention lasted seven months over the winter. The Lactobacillus milk (Gefilus, Valio, Riihimäki, Finland) contained $1 \%$ fat and $5-10 \times 10^{5}$ colony forming units/ml of strain Lactobacillus rhamnosus GG (ATCC 53103). The control milk had the same composition but without Lactobacillus. Milk types were deliverd in cartons coloured yellow or green. The day
Valio Research and
Development,
PO Box 30,
FIN-00039 Valio,
Helsinki, Finland
Katja Hatakka
research nutritionist
Maija Saxelin
senior microbiologist

BMJ 2001;322:1-5 
Foundation for Nutrition Research, PO Box 30,

FIN-00039 Helsinki, Finland

Riitta Korpela

assistant professor

Correspondence to: R Korpela

riitta.korpela@ valio.fi care staff, parents, children, and investigators were unaware of which milk carton contained Lactobacillus until the intention to treat analysis was performed.

The day care staff served the study milks three times a day, five days a week. Every day they reported the amount of milk consumed by each child. The aim was a daily consumption of $200 \mathrm{ml}$. We estimated compliance for milk consumption by calculating the percentage of days during which milk consumption was at least $200 \mathrm{ml}$. Mean compliance was $60 \%$ in both groups. Other products containing probiotic bacteria were forbidden.

\section{Data collection}

We collected background information on the family, their environment, the child's nutrition habits, and illnesses. During the study, parents recorded daily in a symptom diary any respiratory symptoms (fever, runny nose, sore throat, cough, chest wheezes, earache) and gastrointestinal symptoms (diarrhoea, vomiting, stomach ache). They also reported absences from the day care centre, doctors' diagnoses, and prescriptions of antibiotics. A questionnaire at the end of the study collected information on general health and the use of other products that contained lactic acid bacteria during the study. Faecal samples were collected at the beginning, middle, and end of the study. We randomly selected 100 samples to study the recovery of Lactobacillus GG in the faeces to confirm compliance. ${ }^{15} 16$

\section{Sample size and randomisation}

We calculated sample size on the assumption that the use of Lactobacillus GG would result in a $20 \%$ reduction in respiratory tract infections. Pönkä et al reported a mean (SD) of 3.3 (2.3) episodes of illnesses among day care children during an eight month follow up. ${ }^{17}$ We estimated that, with a power of $90 \%$ and at a significance level of 0.05 , we needed 250 children per group to show a $20 \%$ difference between the groups. Each child was randomly allocated to the Lactobacillus or the control group according to a computer generated, blocked randomisation list. We used a block size of four, stratified according to age $(<3$ years and 3 years and over) and day care centre (18 centres).

\section{Outcome measures}

The primary outcome measures were the number of days with respiratory and gastrointestinal symptoms or days with any illness; absences from day care centre because of illness; number of children with upper respiratory tract infections with complications (acute otitis media and sinusitis) and lower respiratory tract infections (acute bronchitis and pneumonia) as diagnosed by a doctor; and antibiotic treatments during the seven month intervention. A secondary outcome was the correlation between the amount of milk consumed and the number of days with symptoms. We also defined a symptom score to measure the overall burden of symptoms (sum of all recorded symptoms, daily range 0 to 9 ).

\section{Statistical analysis}

The distribution of the number of days of illness, days with respiratory and gastrointestinal symptoms, and the symptom scores and days of absence due to illness were skewed to the right and were logarithmically transformed. The results are given as geometric means with $95 \%$ confidence intervals. We used the $t$ test for independent samples to compare the groups. To control for differences in the age distribution, we analysed the logarithmic transformed variables using analysis of covariance, in which we included age as a continuous covariate. We then transformed the age adjusted means and confidence intervals back to the original scales. Treatment differences are given as the geometric mean of the ratio (Lactobacillus:control) with $95 \%$ confidence intervals.

We used Kaplan-Meier survival curves for the time without respiratory symptoms or diarrhoea and the log rank test to compare the groups. We calculated medians with $95 \%$ confidence intervals to describe the time without symptoms. Cox's regression analyses were performed to adjust for confounding factors (such as age). In these analyses we treated values that were missing because of premature withdrawal as censored observations.

The number of upper respiratory infections with complications, lower respiratory infections, and antibiotic treatments were dichotomised (none/one or more) and analysed with the $\chi^{2}$ test or Fisher's exact test. We used logistic regression analyses to control for age. Partial correlations were calculated between milk consumption and the numbers of days with illness, adjusted for age. All analyses were based on the intention to treat population. Statistical analyses were performed with SPSS (release 9.0).

\section{Results}

Of the 594 children randomised, 571 started the study, receiving either milk containing Lactobacillus GG $(n=282)$ or control milk $(n=289)$ (figure 1$)$. Fifty eight children did not complete the follow up period.

Table 1 details characteristics of the children before treatment. The block randomisation resulted in a similar distribution of children in the age groups under 3

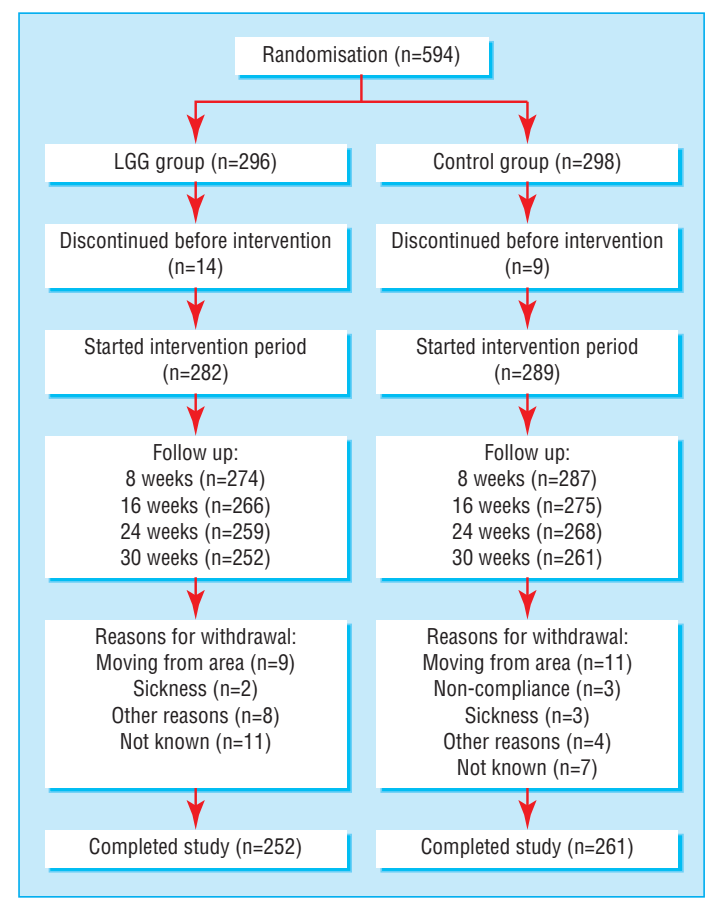

Fig 1 Progress of participants during seven month study 
Table 1 Characteristics before treatment of children allocated to probiotic milk (Lactobacillus $\mathrm{GG}$ ) and control groups. Figures are means (ranges) or numbers (percentage) of children

\begin{tabular}{|c|c|c|}
\hline Characteristic & $\begin{array}{l}\text { Lactobacillus GG } \\
\qquad(\mathrm{n}=282)\end{array}$ & $\begin{array}{l}\text { Control } \\
(\mathrm{n}=289)\end{array}$ \\
\hline Age (years) & $4.6(1.3-6.8)$ & $4.4(1.3-6.7)$ \\
\hline 1 & $16(6)$ & $17(6)$ \\
\hline 2 & $35(12)$ & $38(13)$ \\
\hline 3 & $42(15)$ & $65(23)$ \\
\hline 4 & $62(22)$ & $46(16)$ \\
\hline 5 & $66(23)$ & $81(28)$ \\
\hline 6 & $61(22)$ & $42(14)$ \\
\hline Male & $151(54)$ & $140(48)$ \\
\hline Siblings & $1.1(0-4)$ & $1.0(0-4)$ \\
\hline Duration of breast feeding (months) & $6.8(0-32)$ & $7.1(0-30)$ \\
\hline Duration of day care (months) & $22(0.5-60)$ & $20(0.2-66)$ \\
\hline House area $\left(\mathrm{m}^{2}\right)$ & $90(42-300)$ & $93(34-330)$ \\
\hline Smoking in household & $91(32)$ & $97(34)$ \\
\hline \multicolumn{3}{|l|}{ Health in past 12 months: } \\
\hline \multicolumn{3}{|l|}{ Respiratory infections: } \\
\hline $0-2$ & $140(50)$ & $134(47)$ \\
\hline $3-4$ & $99(36)$ & $86(30)$ \\
\hline$\geqslant 5$ & $38(14)$ & $64(23)$ \\
\hline \multicolumn{3}{|l|}{ Gastrointestinal infections: } \\
\hline $0-1$ & $218(79)$ & $211(75)$ \\
\hline$\geqslant 2$ & $58(21)$ & $69(25)$ \\
\hline \multicolumn{3}{|l|}{ Antibiotic treatments: } \\
\hline $0-1$ & $180(65)$ & $179(64)$ \\
\hline$\geqslant 2$ & $95(35)$ & $101(36)$ \\
\hline \multicolumn{3}{|l|}{ History of allergy (diagnosed by doctor): } \\
\hline Atopic diseases* & $59(21)$ & $64(22)$ \\
\hline Allergic eye infection (\%) & $25(9)$ & $21(7)$ \\
\hline Food allergy (\%) & $24(9)$ & $30(10)$ \\
\hline
\end{tabular}

${ }^{*}$ Allergic rhinitis, atopic eczema, or asthma.

years and 3 years and over: $51(18 \%)$ and $231(82 \%)$ in the Lactobacillus group and $55(19 \%)$ and $234(81 \%)$ in the control group. Detailed analysis of age distribution, however, showed that there were differences between the groups. Also, there were more children in the control group who had had five or more respiratory infections during the preceding 12 months. Age and preceding infections both have an effect on the incidence of infections and as they were strongly correlated we adjusted only for age in comparisons of treatment.

\section{Intention to treat analysis}

Symptoms of illness as reported by parents-There were no significant differences between the groups in the number of days with respiratory and gastrointestinal symptoms (table 2). However, in the Lactobacillus group there were fewer days of absence because of illness-a Lactobacillus:control ratio of 0.85 (95\% confidence
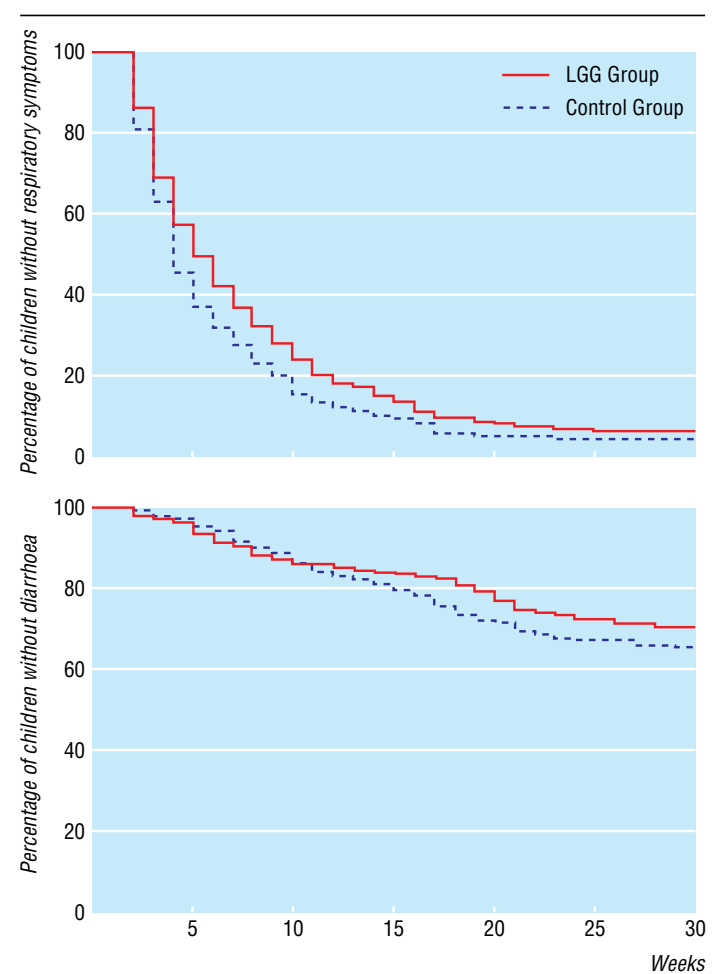

Fig 2 Proportion of children without infection during seven month study (respiratory symptoms and diarrhoea)

interval 0.73 to 0.98 ) - and thus a reduction of $15 \%$. The time without respiratory symptoms was significantly longer in the Lactobacillus group compared with the control group (5 (4.1 to 5.9) v 4 (3.5 to 4.6) weeks, $\mathrm{P}=0.03$, fig 2). Time without diarrhoea was not significantly different (25 (24 to 26$) v 24$ (23 to 25$)$ weeks, respectively, $\mathrm{P}=0.20$, fig 2 ).

Upper and lower respiratory tract infections diagnosed by doctor-The number of children with respiratory infections (otitis media, sinusitis, bronchitis, and pneumonia) was significantly lower in the Lactobacillus group (relative reduction $17 \%$, table 3). There were also fewer children in the Lactobacillus group who were prescribed antibiotics for respiratory infections (relative reduction $19 \%$, table 3 ).

Age adjusted results-Adjustment for age reduced the difference between the groups in the number of days of absence (table 2). After age adjustment the odds ratio for the Lactobacillus group was 0.89 (0.77 to 1.02). The time without respiratory symptoms was not significantly different between the groups (data not

Table 2 Details of symptoms, absence, and symptom score during seven month treatment period. Unadjusted and age adjusted results based on intention to treat population, with children who completed intervention. Figures are geometric means ( $95 \%$ confidence intervals)

\begin{tabular}{|c|c|c|c|c|c|c|}
\hline & \multicolumn{3}{|c|}{ Unadjusted results } & \multicolumn{3}{|c|}{ Age adjusted results } \\
\hline & Lactobacillus $\mathrm{GG}(\mathrm{n}=252)$ & Control $(\mathrm{n}=261)$ & $P$ value* & Lactobacillus $\mathrm{GG}(\mathrm{n}=252)$ & Control $(n=261)$ & P value† \\
\hline Any illness (days) & 25 (22 to 28$)$ & 27 (24 to 30$)$ & 0.22 & 25 (23 to 28$)$ & 26 (24 to 29$)$ & 0.59 \\
\hline Respiratory symptoms (days) & 21 (18 to 24$)$ & 23 (20 to 26$)$ & 0.28 & 21 (19 to 24$)$ & $22(20$ to 25$)$ & 0.67 \\
\hline Gastrointestinal symptoms (days) & 2.9 (2.6 to 3.2$)$ & $3.0(2.7$ to 3.4$)$ & 0.57 & 2.9 (2.7 to 3.2$)$ & $3.0(2.7$ to 3.3$)$ & 0.74 \\
\hline Absence due to illness (days) & 4.9 (4.4 to 5.5$)$ & $5.8(5.3$ to 6.4$)$ & 0.03 & 5.1 (4.6 to 5.6$)$ & $5.7(5.2$ to 6.3$)$ & 0.09 \\
\hline Total symptom score & 34 (30 to 39$)$ & 40 (35 to 46$)$ & 0.10 & $36(32$ to 40$)$ & 39 (34 to 44$)$ & 0.36 \\
\hline
\end{tabular}

${ }^{\star} t$ test for independent samples with log transformed values.

†Analysis of covariance, age included as covariate. 
Table 3 Number (percentage) of children having at least one respiratory tract infection, as diagnosed by doctor, or at least one course of antibiotics prescribed by doctor. Unadjusted and age adjusted results based on intention to treat population with children who completed intervention

\begin{tabular}{|c|c|c|c|c|c|c|}
\hline & \multirow[b]{2}{*}{$\begin{array}{l}\text { Lactobacillus GG } \\
\qquad(\mathrm{n}=252)\end{array}$} & \multirow[b]{2}{*}{$\begin{array}{l}\text { Control } \\
(n=261)\end{array}$} & \multicolumn{2}{|c|}{ Unadjusted comparison } & \multicolumn{2}{|c|}{ Age adjusted comparison } \\
\hline & & & $\begin{array}{l}\text { Absolute \% reduction } \\
(95 \% \mathrm{CI})\end{array}$ & $P$ value* & $\begin{array}{l}\text { Odds ratio } \\
(95 \% \mathrm{CI})\end{array}$ & $P$ value \\
\hline Acute otitis media & $79(31)$ & $101(39)$ & $-7.3(-15.6$ to 0.01$)$ & 0.08 & 0.78 (0.53 to 1.14$)$ & 0.19 \\
\hline Sinusitis & $8(3)$ & $10(4)$ & -0.6 (-3.8 to 2.5$)$ & 0.69 & 0.86 (0.33 to 2.22$)$ & 0.75 \\
\hline Acute bronchitis & $14(6)$ & $19(7)$ & -1.7 (-6.0 to 2.5$)$ & 0.43 & 0.80 (0.39 to 1.64$)$ & 0.54 \\
\hline Pneumonia & $3(1)$ & $4(2)$ & $-0.3(-2.4$ to 1.7$)$ & 1.00 & 0.83 (0.18 to 3.78$)$ & 0.81 \\
\hline All infections together & $97(39)$ & $123(47)$ & $-8.6(-17.2$ to -0.1$)$ & 0.05 & 0.75 (0.52 to 1.09$)$ & 0.13 \\
\hline $\begin{array}{l}\text { Antibiotic treatments for } \\
\text { respiratory infections }\end{array}$ & $111(44)$ & $140(54)$ & $-9.6(-18.2$ to -1.0$)$ & 0.03 & $0.72(0.50$ to 1.03$)$ & 0.08 \\
\hline All antibiotic treatments & $119(47)$ & $144(55)$ & $-8.0(-16.6$ to 1.0$)$ & 0.07 & 0.78 (0.54 to 1.11$)$ & 0.17 \\
\hline
\end{tabular}

${ }^{*} \chi^{2}$ test or Fisher's exact test.

†Logistic regression analysis, age included as covariate.

shown), but for the Lactobacillus group the estimated odds ratio was 0.86 ( 0.70 to $1.06, \mathrm{P}=0.16)$, indicating reduced risk. Time without diarrhoea was also not significantly different between the groups, but the odds ratio for the Lactobacillus group was 0.87 (0.64 to 1.28, $\mathrm{P}=0.36$ ). The numbers of children with respiratory tract infections diagnosed by a doctor and being given antibiotic treatments for these were not significantly different between the groups (table 3). However, the age adjusted odds ratios for the Lactobacillus group were $0.75(0.52$ to $1.09, \mathrm{P}=0.13)$ for all respiratory infections and 0.72 ( 0.50 to $1.03, \mathrm{P}=0.08)$ for antibiotic treatment for respiratory infection.

\section{Secondary analyses}

After age adjustment there was a negative but non-significant correlation between the amount of milk consumed and the total number of days of illness $(r=-0.12 ; \quad \mathrm{P}=0.07)$ and days with respiratory symptoms $(r=-0.11 ; \mathrm{P}=0.09)$. The negative correlation between the amount of Lactobacillus milk consumed and days with gastrointestinal symptoms was significant $(r=-0.17 ; \mathrm{P}=0.007)$.

Mean daily milk consumption was $260 \mathrm{ml}$ in both groups (range 110-520 $\mathrm{ml}$ in the Lactobacillus and 100$600 \mathrm{ml}$ in the control group). This quantity of milk contained 1-2x $10^{8}$ cfu of Lactobacillus GG. Compliance was also measured by the faecal recovery of Lactobacillus. Initially $12 \%$ of children in the Lactobacillus group and $4 \%$ in the control group carried Lactobacillus GG-type bacteria $(\mathrm{P}=0.29)$. Recovery figures were $97 \%$ v $9 \%(\mathrm{P}<0.0001)$, respectively, in the middle of the study and $91 \% v 15 \%(\mathrm{P}<0.0001)$ at the end. The median faecal Lactobacillus GG count in the Lactobacillus group was $5-8 \times 10^{4} \mathrm{cfu} / \mathrm{g}$.

The responses to the questionnaire at the end of the study were similar in both groups. Neither Lactobacillus nor the control milk affected stool frequency or consistency. There was no difference between the groups in abdominal pain or allergic symptoms and no apparent side effects.

\section{Discussion}

This randomised, double blind, placebo controlled study is the first to examine the long term effects of probiotic bacteria on infections in normally healthy children. The intervention lasted seven months during the season in which the infection rate is usually highest. ${ }^{18}$ Fewer children in the group taking
Lactobacillus GG suffered from respiratory infections with complications, though there was no significant difference between the groups in the number of days with symptoms. We found a reduction of $21 \%$ in the occurrence of acute otitis media in the Lactobacillus group, although the difference between the groups was not significant. Complications from respiratory infections were the main indication $(85 \%)$ for the use of antibiotics. Consuming Lactobacillus GG reduced such treatments. Children receiving Lactobacillus had fewer days of absence from day care because of illness, suggesting that Lactobacillus GG may lessen the severity of respiratory infections.

It is well known that age is strongly associated with the incidence of infection. ${ }^{19}$ We noticed that despite the age stratified randomisation, there were differences in the age distributions between the study groups. Although neither the mean age nor the distribution between those aged under 3 and 3 years and over differed between the groups, there were more 3 and 5 year olds in the control group and more 4 and 6 year olds in the Lactobacillus group. Because of this unintentional distribution we adjusted the analyses for age, which reduced the differences between the groups. However, the results came close to conventional significance, and the differences were consistently in favour of the Lactobacillus GG group.

\section{Mode of action}

Lactobacillus GG may influence the incidence of infections by stimulating non-specific immunity or enhancing humoral and cellular immunity. ${ }^{20}$ This immunostimulatory effect of bacteria has previously been shown to prevent recurrent infections in children attending day care centres. ${ }^{21}$ Our finding of negative correlation between the days with gastrointestinal symptoms and the dose of Lactobacillus milk consumed may indicate a dose dependent response.

The compliance in our study was good, as measured by milk consumption, number of drop outs, and faecal recovery of Lactobacillus GG (most of the children in the Lactobacillus group carried Lactobacillus GG). Because Lactobacillus GG products are widely consumed in Finland, the children in the control group may unwittingly have consumed Lactobacillus during the study. At the end of the study, Lactobacillus GG-like bacteria were found in $15 \%$ of the children in the control group, which could have reduced the actual differences between the groups. 


\section{What is already known on this topic}

Children attending day care centres are at high risk of respiratory and gastrointestinal infection

The successful prevention of respiratory infections could be extremely useful for families and for society in general

Short term use of probiotic bacteria has been shown to reduce the severity of rotavirus diarrhoea and the incidence of diarrhoea associated with the use of antibiotics

\section{What this study adds}

In a double blind, randomised, long term study milk containing Lactobacillus GG slightly reduced the incidence of respiratory infections and antibiotic treatment in children

\section{Socioeconomic effects}

Respiratory infections in children have a major impact on families and on society in general. In 1985 and 1986 , the annual cost to society in general due to illness in children attending Finnish day care centres was about $£ 650$ to $£ 2300$ per child, depending on age. ${ }^{8}$ Thus a $10-20 \%$ reduction in the incidence of infections and absences from day care centres, which our results indicate is possible, could have important clinical, public health, and economic consequences.

Alternative programmes for preventing respiratory tract infections in children are much needed. The administration of probiotic milk products is an easy and acceptable method, with no adverse effects. Our results show that probiotic milk containing Lactobacillus GG may reduce respiratory infections and their complications among children attending day care centres.

We thank research assistant Ms Anne Nyberg for arranging the intervention and creating the database; Ms Mimi Ponsonby for language editing; and the Social Department of Helsinki City, the day care centre staff, the children, and their parents for making this study possible.

Contributors: KH designed the protocol and the questionnaires, participated in the creation of the database, and wrote the paper. ES supervised the study and revised the manuscript. TP was responsible for the data analysis and wrote the sections on statistical methods. AP, JHM, and LN participated in the planning of the study and revised the manuscript. RK and MS initiated the study, participated in the planning, were responsible for the management of the study, and revised the manuscript. KH and RK are the guarantors of the paper.
Funding: Valio Research and Development, Helsinki, Finland. The University of Helsinki and the City of Helsinki participated in the funding by providing supervision and technical help.

Competing interests: $\mathrm{KH}$ has been employed by Valio Research Centre for two of the past five years. MS and RK are employed by Valio Research Centre. ES has given two educational presentations on Lactobacillus GG for Valio, and TP has received consulting fees from Valio.

1 Wald ER, Guerra N, Byers C. Frequency and severity of infections in day care: three-year follow-up. J Pediatr 1991;118:509-14

2 Collet JP, Burtin P, Gillet J, Bossard N, Ducruet T, Durr F. Risk of infectious diseases in children attending different types of day-care setting. Respiration 1994:61(suppl 1):16-9.

3 Louhiala PJ, Jaakkola N, Ruotsalainen R, Jaakkola JJK. Form of day care and respiratory infections among Finnish children. Am J Public Health $1995 ; 85: 1109-12$

4 Churchill RB, Pickering LK. Infection control challenges in child-care centers. Infect Dis Clin North Am 1997;11:347-65.

5 Louhiala PJ, Jaakkola N, Ruotsalainen R, Jaakkola JJK. Day-care center and diarrhea: a public health perspective. J Pediatr 1997;131:476-9.

6 Nafstad P, Hagen JA, Oie L, Magnus P, Jaakkola JJK. Day care centers and respiratory health. Pediatrics 1999;103:753-8.

7 Bell DM, Gleiber DW, Mercer AA, Phifer R, Guinter RH, Cohen AJ, et al. Illness associated with child day care: a study of incidence and cost. Am J Public Health 1989;79:479-84.

8 Nurmi T, Salminen E, Pönkä A. Infections and other illnesses of children in day-care centers in Helsinki. II: the economic losses. Infection 1991:19:331-5.

9 Carabin H, Gyorkos TW, Soto JC, Penrod J, Joseph L, Collet J-P. Estimation of direct and indirect costs because of common infections in toddlers attending day care centers. Pediatrics 1999;103:556-64.

10 Saxelin M. Lactobacillus GG-a human probiotic strain with thorough clinical documentation. Food Rev Int 1997;13:293-313.

11 Kaila M, Isolauri E, Soppi E, Virtanen E, Laine S, Arvilommi H. Enhancement of the circulating antibody secreting cell response in human diarrhea by a human lactobacillus strain. Pediatr Res 1992:32:141-4.

12 Pelto L, Isolauri E, Lilius E-M, Nuutila J, Salminen S. Probiotic bacteria down-regulate the milk-induced inflammatory response in milkhypersensitive subjects but have an immunostimulatory effect in healthy subjects. Clin Exp Allergy 1998;28:1474-9.

13 Arvola T, Laiho K, Torkkeli S, Mykkänen H, Salminen S, Maunula L, et al. Prophylactic Lactobacillus GG reduces antibiotic-associated diarrhea in children with respiratory infections: a randomized study. Pediatrics 1999;104:e64.

14 Vanderhoof JA, Whitney DB, Antonson DL, Hanner TL, Lupo JV, Young $\mathrm{RJ}$. Lactobacillus GG in the prevention of antibiotic-associated diarrhea in children. J Pediatr 1999;135:564-8.

15 Siitonen S, Vapaatalo H, Salminen S, Gordin A, Saxelin M, Wikberg R, et al. Effect of lactobacillus GG yoghurt in prevention of antibiotic associated diarrhoea. Ann Med 1990; 22:57-9.

16 Tynkkynen S, Satokari R, Saarela M, Mattila-Sandholm T, Saxelin M. Comparison of ribotyping, randomly amplified polymorphic DNA analyses, and pulsed-field gel electrophoresis in typing of Lactobacillus rhamnosus and L casei strains. Appl Environ Microbiol 1999;65:3908-14.

17 Pönkä A, Salminen E, Nykänen M, Dahlbom M, Nurmi T. Lasten sairastavuus päiväkodeissa ja ryhmäperhepäiväkodeissa. Suomen Lääkärileht 1994;49:3579-83.

18 Möttönen M, Uhari M. Absences for sickness among children in day care. Acta Pediatr 1992:81:929-32.

19 Pönkä A, Nurmi T, Salminen E, Nykyri E Infections and other illnesses of children in day-care centers in Helsinki. I: Incidences and effects of home and day-care center variables. Infection 1991;19:230-6.

20 Erickson KL, Hubbard NE. Probiotic immunomodulation in health and disease. J Nutr 2000;130:403-9S

21 Collet JP, Ducruet T, Kramer MS, Haggerty J, Floret D, Chomel JJ, et al. Stimulation of nonspecific immunity to reduce the risk of recurrent infections in children attending day-care centers. Pediatr Infect Dis J 1993;12:648-52.

(Accepted 14 March 2001) 